\title{
CARACTERIZACIÓN MORFOLÓGICA DEL XII CICLO DE SELECCIÓN DEL MAÍZ CUZQUEADO EN EL VALLE DEL MANTARO $^{26}$
}

\author{
Gilberto Gamarra Sánchez 27
}

Facultad de Agronomía de la Universidad Nacional del Centro del Perú

\begin{abstract}
RESUMEN
Con el propósito de obtener una población de maíz Cuzco adaptada a las condiciones del valle del Mantaro, se utilizó una mezcla de colecciones de la raza de maíz Cuzco formando un compuesto con características definidas, habiéndose realizado el Mejoramiento Genético durante doce ciclos de selección intrapoblacional (Selección masal estratificada) ${ }^{4}$ desde 1996 hasta el año 2008 en el distrito de Hualhuas, provincia de Huancayo, departamento de Junín a 3,320 msnm. La selección recurrente de un ciclo por año con definido criterio ha permitido obtener una población de maíz fenotípicamente homogénea, pero lo suficientemente heterocigota para los loci que controlan características determinantes del rendimiento. Al mantener suficiente variabilidad genética del compuesto se garantiza la eficiente recombinación genética con una población numerosa superando los problemas propios de la especie como la endogamia. El doceavo ciclo de selección permite definir la morfología de planta con ocho características: días a la floración masculina con un promedio de 105 , días a la floración femenina con un promedio de 108, altura de mazórca con un promedio de $145.795 \mathrm{~cm}$., altura de planta con un promedio de $243.125 \mathrm{~cm}$., número de hojas con un promedio de 13.35 , longitud de mazorca sin despancar (choclo) con un promedio de 33.275, número de hileras por mazorca con un promedio de 9.1, número de granos por hilera con un promedio de 28.625. Los ecotipos que forman un compuesto pueden ser definidos como poblaciones localmente adaptadas pertenecientes a especies con amplio rango geográfico. Son poblaciones de plantas con características hereditarias similares, producidas por adaptación a un hábitat determinado. Los caracteres heredables pueden ser morfológicos y fisiológicos. Las fisiológicas como precocidad, resistencia al frío, rusticidad, etc. son de gran importancia en determinar las diferencias entre los ecotipos, debido al gran valor que tiene para la supervivencia. La semilla obtenida en el núcleo de selección es utilizada para incrementar la semilla certificada, la cual cada año es entregada a los agricultores con resultados óptimos.
\end{abstract}

Palabras clave: Caracterización morfológica, población, ciclos de selección.

\section{MORPHOLOGICAL CHARACTERIZATION OF THE CYCLE XII SELECTION OF CUZQUEADO CORN IN THE MANTARO VALLEY}

\begin{abstract}
In order to obtain a population of Cuzco maize adapted to the conditions of the Mantaro Valley, it was used a mixture of collections of Cuzco maize race to form a compound with defined characteristics, having made the Genetic Improvement for twelve cycles of selection within populations ( stratified mass selection) 4 from 1996 to 2008 in Hualhuas district, province of Huancayo, Junín Department of 3.320 meters osl. Recurrent selection cycles per year with defined criteria has yielded a phenotypically homogeneous population of corn but sufficiently heterozygous for loci controlling determinants of performance characteristics. To maintain sufficient genetic variability composite ensured efficient recombination with a large population, overcoming the problems of the species as inbreeding. The twelfth round of selection to define the morphology of plant with eight traits: days to flowering male with an average of 105 days to flowering female with an average of 108 , ear height with an average of $145,795 \mathrm{~cm}$., Height plant with an average of $243,125 \mathrm{~cm}$., number of leaves with an average of 13.35 , ear length without despancar (corn) with an average of 33,275 , number of rows per ear with an average of 9.1 , number of kernels per row with a average of 28,625 . Ecotypes forming a compound can be defined as locally adapted populations belonging to species with wide geographic range. Plant populations are inherited characteristics like, produced by adaptation to a particular habitat. Heritable traits can be morphological and physiological. The physiological and earliness, hardiness, hardiness, etc.. are of great importance in determining the differences between the ecotypes, due to the large value to survival. The seeds obtained in the nucleus of selection is used to raise certified seed, which is given annually to farmers with optimal results.
\end{abstract}

Key words: Morphological, population, cycles of selection.

\footnotetext{
26 Trabajo de investigación fue recibido el 07/05/2010 retornado para su revisión el 15/06/2010 y aprobado para su publicación 16/11/2010

${ }^{27}$ gilbergs@hotmail.com
} 


\section{INTRODUCCIÓN}

El Valle del Mantaro es fuente inagotable de alimentos para la capital y zonas que no gozan de cultivos como el maíz que provee diversidad de formas para satisfacer la necesidad alimentaria del país. La raza de maíz Cuzco se cultiva en el Valle, principalmente para choclo y pocas veces para grano seco, existiendo el hábito de comprar semilla directamente del Cuzco. Sin embargo, por efecto de la interacción genotipo medio ambiente presenta dificultades para su adaptación con plantas demasiado altas, acame, bajo llenado de grano en la mazorca, ataque de enfermedades, producción tardía y falta de calidad (sabor y aspecto de mazorca) ${ }^{7}$. El cultivo de maíz para choclo en el valle del Mantaro en los últimos años se ha incrementado de manera sostenida, utilizando los agricultores semilla del valle del Urubamba que presenta características de producción tardía ( 7 meses choclo) abundante masa de planta y caña gruesa (con unos 18 hojas por planta), altura de planta alta ( mayor a $3.20 \mathrm{~m}$.), pedúnculo de mazorca muy larga (cachudo) y número de granos por hilera de mazorca menor de 26 , paralelo a ello saturación de mercado por la época de siembra agrupada en el mes de agosto y septiembre. Motivo por el cual se busca un genotipo que conserve los rendimientos del Maíz Cuzco original, que tenga precocidad comprobada (seis meses para choclo y ocho para maíz seco), masa foliar reducida, uniformidad de hileras de mazorca, número de granos por hilera de mazorcas mayor de 28 , calidad de mazorca en choclo y seco y tamaño de grano grande 1 . El objetivo del presente trabajo de investigación fue caracterizar morfológicamente el doceavo ciclo de selección de maíz cuzqueado planteándose la hipótesis de establecer un ideotipo de planta con parámetros definidos con componentes del rendimiento y calidad

\section{MATERIALES Y MÉTODOS}

El trabajo de investigación se realizó en la sierra alta del Perú, distrito de Hualhuas, ubicado en la provincia de Huancayo, departamento de Junín L.S. $12^{\circ} 35^{\prime}$ del Ecuador; L.W. $75^{\circ} 15^{\prime}$ de Greenwich; altitud: 3320 m.s.n.m. El trabajo de investigación se inició en el mes de junio del 2007 con la elaboración del proyecto, culminando con el procesamiento de datos y elaboración del informe final en junio del 2008. El material genético original estuvo conformado por la colección de diferentes tipos de maíces de la raza Blanco Urubamba con cierta adaptación al valle del Mantaro. Es decir se colectó de la cosecha de agricultores que introdujeron semilla directamente del Cuzco desde el año 1993, lo cual significa diferentes tendencias de conservación y mantenimiento del germoplasma e indirectamente la mezcla con cultivares de la región como el maíz San Gerónimo y sus variaciones.

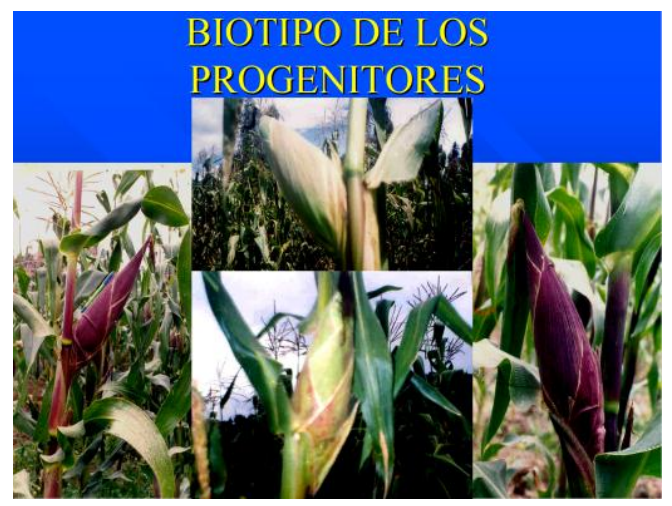

Fotografía 1.- Biotipo de los progenitores

Se empleó una parcela experimental de observación, con un área de $40 \times 40$ metros, sembrándose semilla del núcleo seleccionado la campaña agrícola anterior, luego se realizó las evaluaciones tomándose al azar 40 plantas para cada una de las características. Las condiciones de manejo agronómico propios del maíz cuzqueado fueron uniformes para todo el experimento.

$\begin{array}{lll}\text { Número de experimentos : } & 1 & \\ \text { Número de surcos por parcela } & : & 50 \\ \text { Longitud de surco } & : & 40 \mathrm{~m} \\ \text { Ancho de surco } & : & 0.80 \mathrm{~m} \\ \begin{array}{l}\text { Número de golpes por surco } \\ \text { Número de semillas por golpe }\end{array} & : & 100 \\ \begin{array}{l}\text { Distancia entre golpes } \\ \text { Área por parcela }\end{array} & 0.40 \mathrm{~m} & 2 \\ \mathrm{~m}^{2} & : & 1600\end{array}$

En el presente trabajo se utilizó el método experimental aplicado al mejoramiento genético, mediante la observación, descripción y explicación de los fenómenos que acontecen durante el proceso de investigación, básicamente de las siguientes características:

1) Días a la floración masculina: El número de días transcurrido entre la siembra y el momento en que el $50 \%$ de las plantas de la parcela se encuentran produciendo polen.

2) Días a la floración femenina: El número de días transcurrido entre la siembra y el momento en que el $50 \%$ de las plantas de la parcela se encuentren emitiendo estigmas receptivos.

3) Altura de mazorca: En centímetros desde el suelo hasta el nudo de inserción de la mazorca superior, 
promedio de cuarenta plantas representativas de la parcela.

4) Altura de planta: En centímetros desde el suelo hasta el nudo de inserción del pedúnculo de la inflorescencia masculina, promedio de cuarenta plantas representativas de la parcela.

5) Número de hojas: Se contabilizará en promedio de cuarenta plantas tomadas al azar.

6) Longitud de mazorca (choclo): En centímetros, en promedio de cuarenta mazorcas tomadas al azar.

7) Número de hileras por mazorca: En promedio de cuarenta mazorcas tomadas al azar.

8) Número de granos por hilera: En promedio de cuarenta mazorcas tomadas al azar.

\section{RESULTADOS}

Según el Cuadro $\mathrm{N}^{\circ} \mathbf{1}$, para días a la floración masculina se tiene una media de 105 días fluctuando entre 104 y 106 días para la muestra tomada. Asimismo el coeficiente de variación de 0.51 señala una muestra homogénea para el carácter como se observa en el Gráfico 1.

Cuadro 1.- Media y variancia de días a la floración masculina

\begin{tabular}{|c|c|c|}
\hline Característica & Media & Variancia \\
\hline $\begin{array}{l}\text { Días a la floración } \\
\text { masculina }\end{array}$ & 105 & 0.51 \\
\hline
\end{tabular}

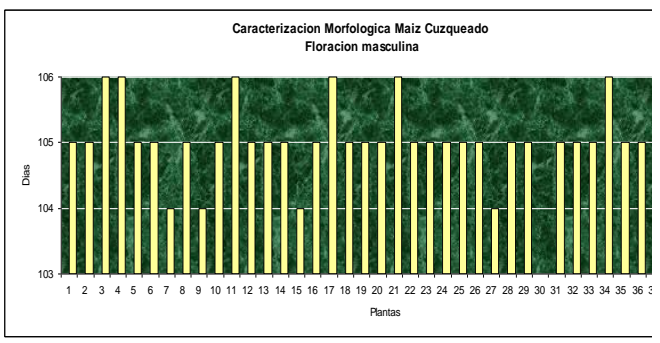

Gráfico 1.-Variabilidad fenotípica de días a la floración masculina.

Asimismo el Cuadro $\mathbf{N}^{\circ}$ 2, para días a la floración femenina se tiene una media de 108 días fluctuando entre 106 y 109 días para la muestra tomada. El coeficiente de variación de 0.67 señala una muestra homogénea para el carácter como se observa en el Gráfico 2.

Cuadro 2.- Media y variancia de días a la floración femenina

\begin{tabular}{ccc}
\hline Característica & Media & Variancia \\
\hline Días a la & 108 & 0.67 \\
floración & & \\
femenina & & \\
\hline
\end{tabular}

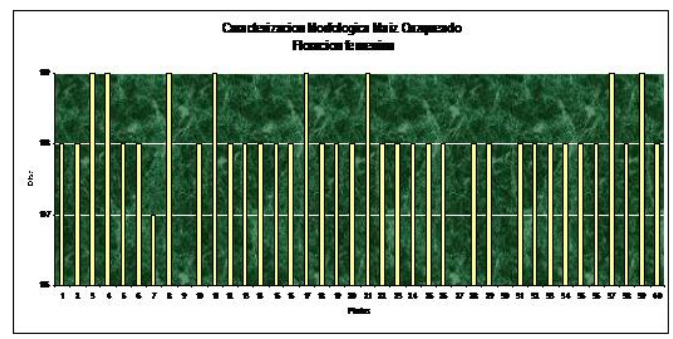

\section{Gráfico 2: Variabilidad fenotípica de días a la floración femenina.}

El Cuadro $\mathrm{N}^{\circ}$ 3, para altura de mazorca se tiene una media de $145.975 \mathrm{~cm}$. con un valor mínimo de $1.20 \mathrm{y}$ máximo de $1.89 \mathrm{~cm}$. respectivamente. La amplitud de ubicación de 69 centímetros es de gran variabilidad como lo indica la variancia, sin embargo, se considera este factor propio de la variedad dependiendo si la mazorca se ubica en la sexta, séptima u octava hoja. Gráfico 3

Cuadro $\mathrm{N}^{\circ}$ 3: Media y variancia de altura de mazorca

\begin{tabular}{ccc}
\hline Característica & Media & Variancia \\
\hline Altura de mazorca & 145.975 & 245.25 \\
\hline
\end{tabular}

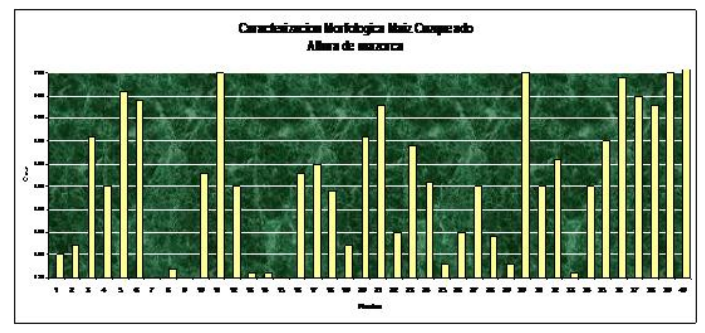

\section{Gráfico 3: Variabilidad fenotípica de altura de mazorca.}

Para altura de planta tomada a los 135 días según el Cuadro $\mathrm{N}^{\circ}$ 4, se tiene una media de 243.125 centímetros, calificada como planta de porte medianamente alto cuyos valores fluctúan entre $210 \mathrm{y}$ 270 centímetros respectivamente. Gráfico 4. La variancia de 197.49 alto, nos señala una muestra heterogénea, es decir la eficiencia de crecimiento es variable entre los individuos. 
Cuadro 4: Media y varianza de altura de planta

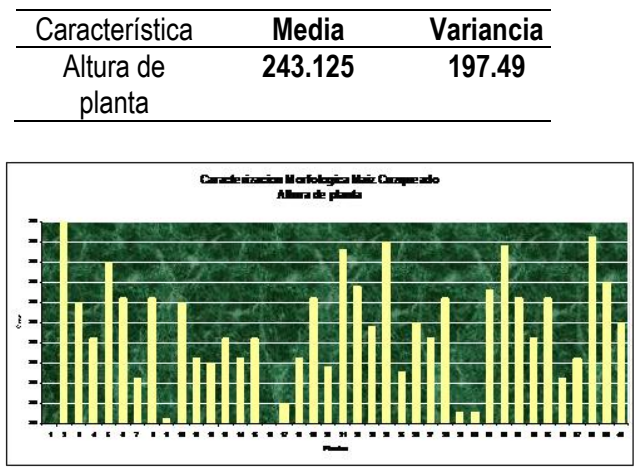

Gráfico 4: Variabilidad fenotípica de altura de planta.

Asimismo el Cuadro $\mathbf{N}^{\circ} \mathbf{5}$, para número de hojas se obtiene una media de 13.35 hojas con valores entre 12 y 15 para la muestra tomada. El coeficiente de variación de 1.26 indica que esta característica es fundamental en el fenotipo de planta Gráfico 5 .

Cuadro $\mathrm{N}^{\circ}$ 5: Media y variancia de número de hojas

\begin{tabular}{ccc}
\hline Característica & Media & Variancia \\
\hline $\begin{array}{c}\text { Número de } \\
\text { hojas }\end{array}$ & 13.35 & 1.26 \\
\hline
\end{tabular}

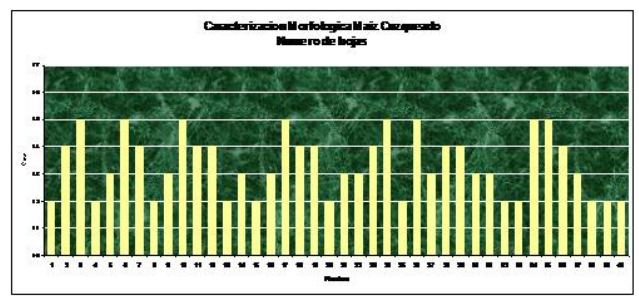

Gráfico 5: Variabilidad fenotípica de número de hojas.

Para longitud de mazorca choclo el CUADRO 6 nos señala una media de 33.275 centímetros, carácter que la hace atractiva y aparente para su comercialización en fresco fluctuando entre 28 y 40 centímetros respectivamente para la muestra tomada. El coeficiente de variación de 7.69 señala una muestra homogénea para el carácter como se observa en el Gráfico 6.

Cuadro $\mathrm{N}^{\circ} 6$ : Media y variancia de longitud de mazorca

\begin{tabular}{lcc}
\hline Característica & Media & Variancia \\
\hline Longitud de & 33.275 & 7.69 \\
\hline
\end{tabular}

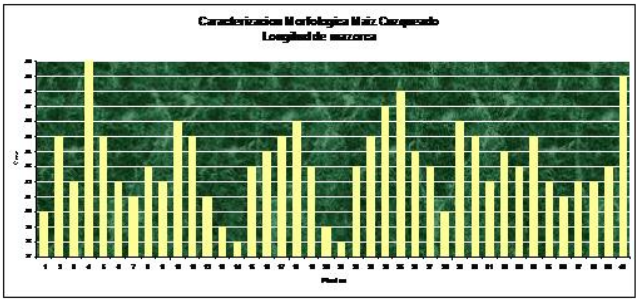

Gráfico 6: Variabilidad fenotípica de longitud de mazorca.

El número de hileras por mazorca para la población Maíz Cuzqueado presenta la peculiaridad de manifestar tres tipos: de ocho, diez y doce hileras. El promedio de 9.1 hileras por mazorca distingue a la población según el Cuadro $N^{\circ} 7$ y Grafico 7.

Cuadro $N^{\circ} 7$ : Media y variancia de número de hileras por mazorca

\begin{tabular}{ccc}
\hline Característica & Medias & Variancia \\
\hline $\begin{array}{c}\text { Número de hileras } \\
\text { por mazorca }\end{array}$ & 9.1 & 2.45 \\
\hline
\end{tabular}

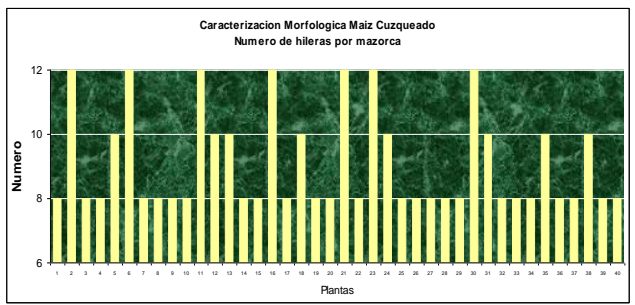

Gráfico 7: Variabilidad fenotípica de número de hileras por mazorca.

Finalmente el Cuadro $\mathbf{N}^{\circ} 8$, para número de granos por hilera de la mazorca presenta una media de 28.625 granos, con valores entre 22 y 35 granos por hileras para la muestra tomada. El coeficiente de variación de 9.63 señala una muestra homogénea para el carácter como se observa en el Gráfico 8.

Cuadro $N^{\circ} 8$ : Media y variancia de número de granos por hilera.

\begin{tabular}{ccc}
\hline Característica & Media & Variancia \\
\hline $\begin{array}{c}\text { Número de granos por } \\
\text { hilera }\end{array}$ & 28.625 & 9.63 \\
\hline
\end{tabular}




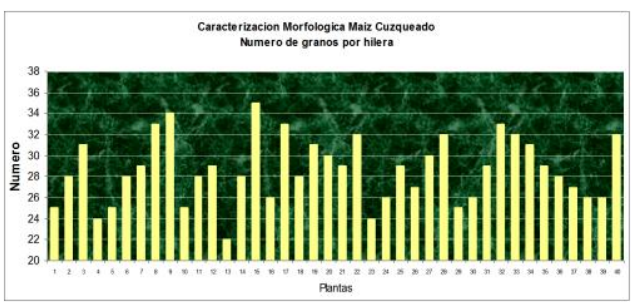

Gráfico 8: Variabilidad fenotípica de número de granos por hilera.

\section{DISCUSIÓN}

El inicio de la floración masculina predomina sobre la floración femenina pudiéndose calificar a la población como predominantemente protoándrica. ${ }^{9}$ Fotografía 2.

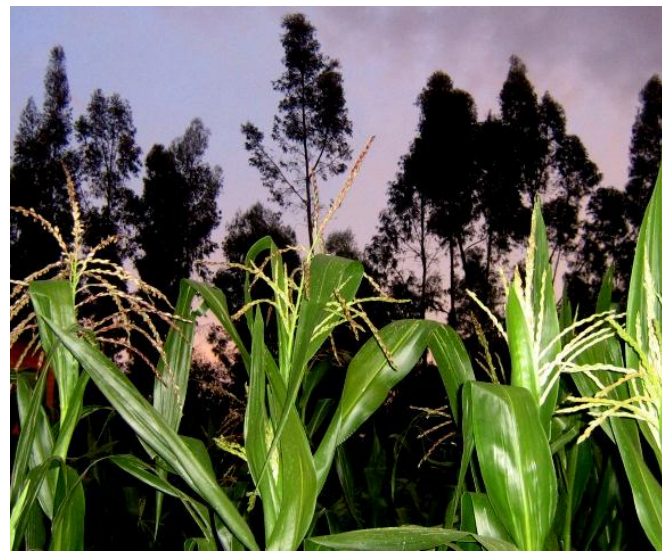

Fotografía 2: Floración masculina de maíz cuzqueado

La diseminación del polen en toda la población se extiende por un promedio de cuarenta días, ello asegura la adecuada fertilización de las inflorescencias femeninas.

La floración femenina en condiciones ambientales adecuadas asegura la fertilización de los óvulos y la adecuada recombinación genética de los individuos de la población. Fotografía 3.

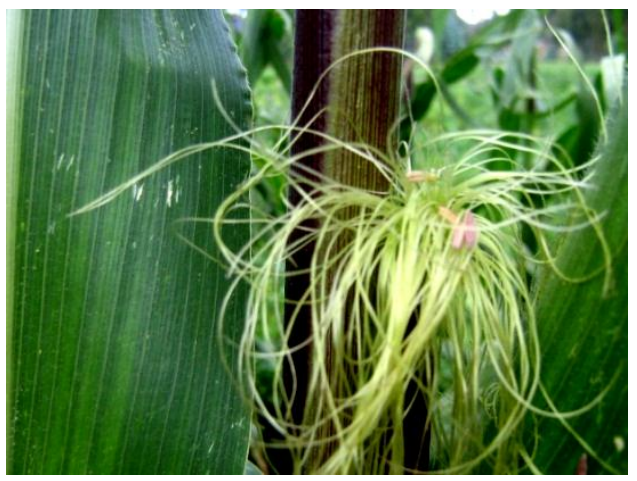

Fotografía 3: Floración femenina de maíz cuzqueado

La Fotografía 4 nos ilustra acerca de la ubicación de la mazorca principal. Sevilla y Salhuana ${ }^{7}$ analizaron el comportamiento de la variedad Blanco Urubamba sembrada en Junín durante tres ciclos sucesivos. . La altura de mazorca se redujo de $0.91 \mathrm{~m}$. en la población original a $0.82 \mathrm{~m}$. en la progenie del segundo año. Ellos explican este cambio como un mecanismo de adaptación al frío.

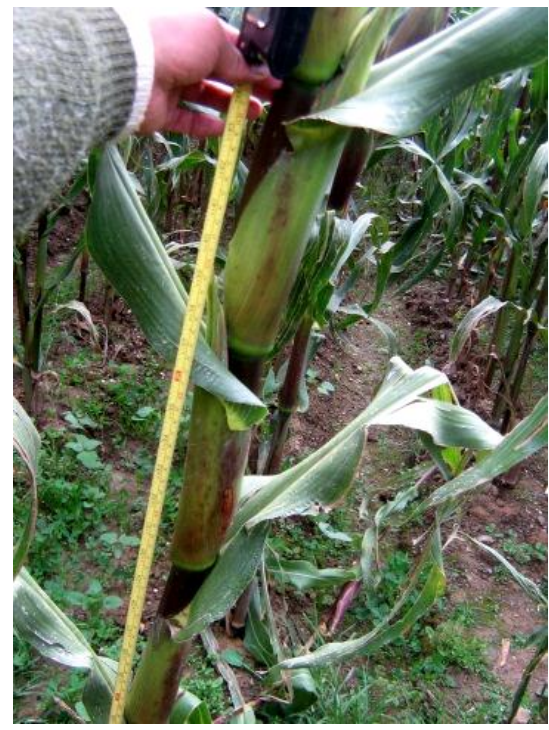

Fotografía 4: Altura de mazorca de maíz cuzqueado Como se observa en la Fotografía 5 la población a los 180 días manifiesta la altura de planta en términos homogéneos esto debido a que la planta continua en crecimiento hasta culminar su ciclo reproductivo que concluye con el cuajado del grano. La media para altura de planta se explica como un mecanismo de adaptación al frío, es decir conforme avanzan los ciclos de 
selección la frecuencia de genes favorables para este carácter se van acumulando gradualmente en las poblaciones. $^{2}$

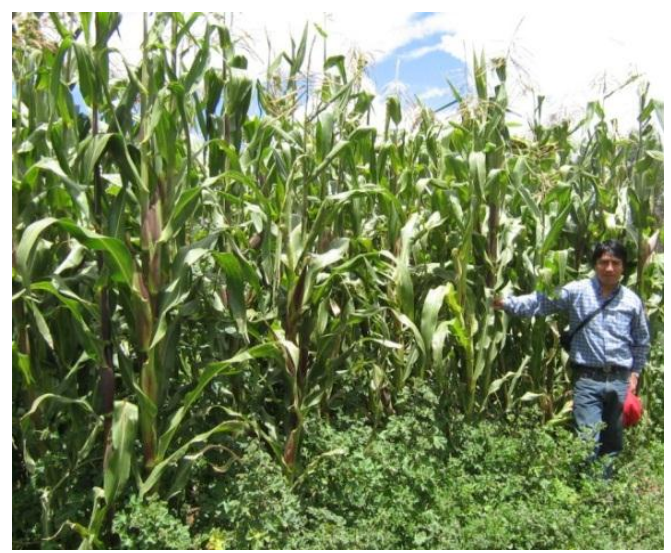

Fotografía 5: Altura de planta de maíz cuzqueado

Respecto al número de hojas, el promedio obtenido como se observa en la Fotografía 6 es mucho menor al Maíz Cuzco original ${ }^{1}$ de 16 hojas; este carácter es el resultado de la adaptación de los individuos a una zona diferente a su origen generando cambios morfológicos propios de la población seleccionada.

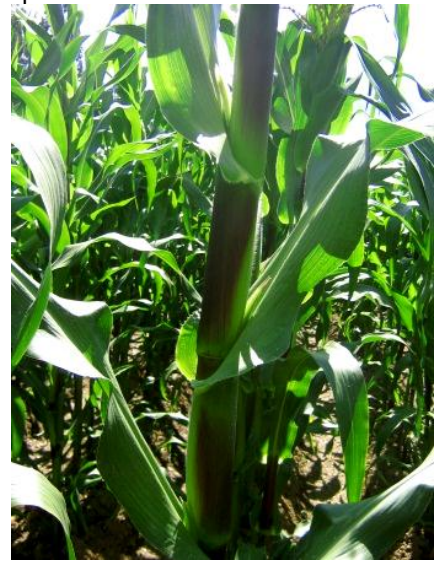

Fotografía 6: Número de hojas de maíz cuzqueado

El tamaño de la mazorca es fundamental en el proceso productivo, ya que su promedio representa un carácter cuantitativo importante para el comercio tal como se observa en la Fotografía 7.

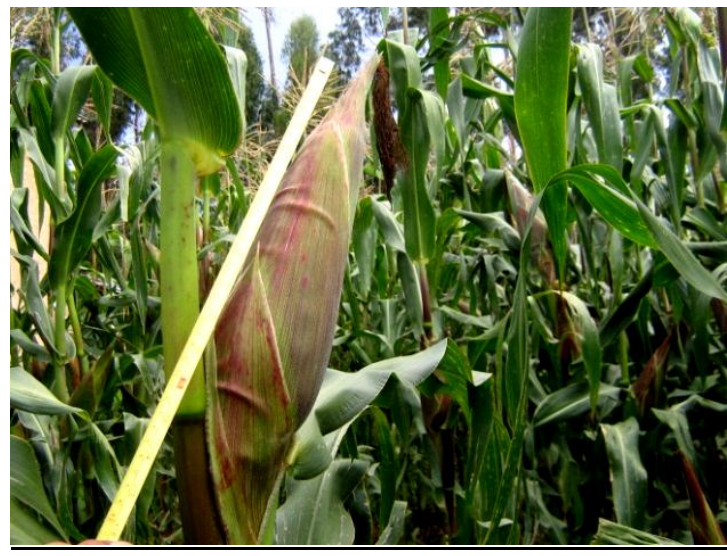

Fotografía 7: Longitud de mazorca de maíz cuzqueado

La base genética de mantener tres tipos de mazorca en la población apoya la teoría de la estructura genética del maíz que es predominantemente heterocigota para los loci que controlan los diversos caracteres, y para el carácter en estudio los sucesivos ciclos de selección han permitido observar su amplia recombinación y segregación asegurando una enorme variabilidad genética Las Fotografías 8, 9, 10 y 11 respectivamente ilustran los tipos de mazorcas por el número de hileras.

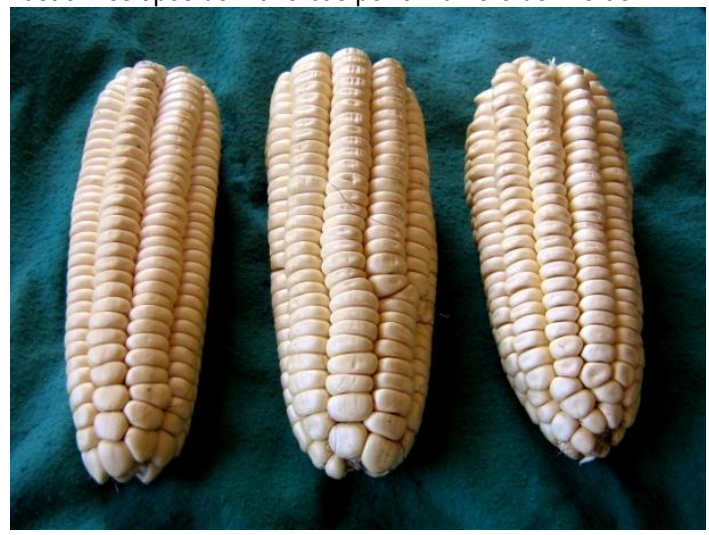

Fotografía 8: Tipos de mazorcas con ocho, diez y doce hileras de maíz cuzqueado 


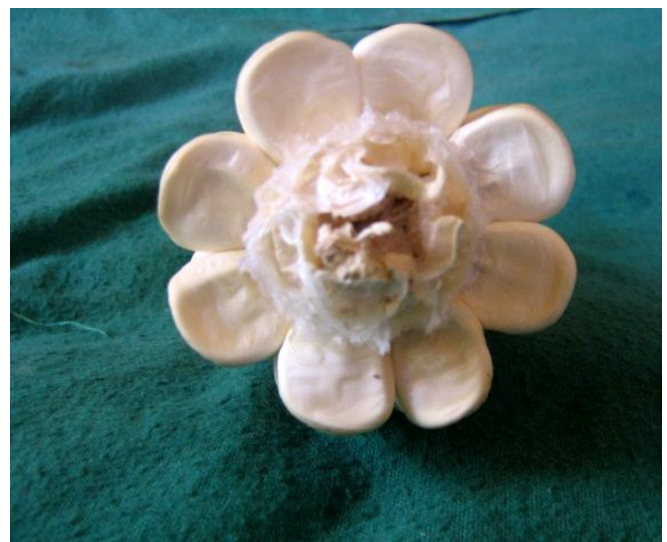

Fotografía 9: Número de hileras OCHO de maíz cuzqueado

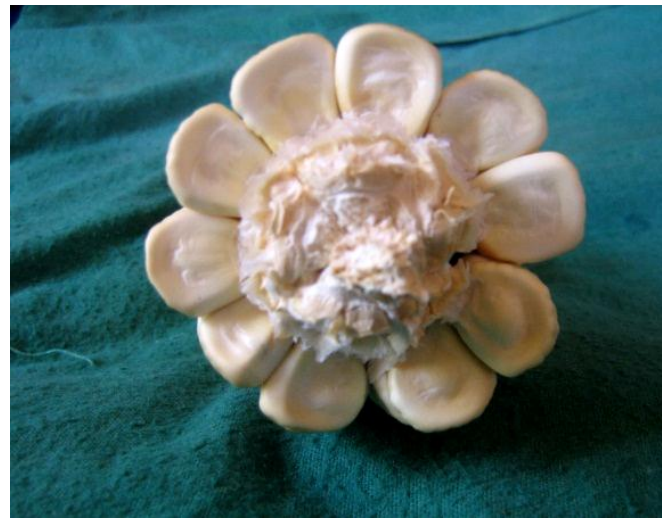

Fotografía 10: Número de hileras DIEZ de maíz cuzqueado

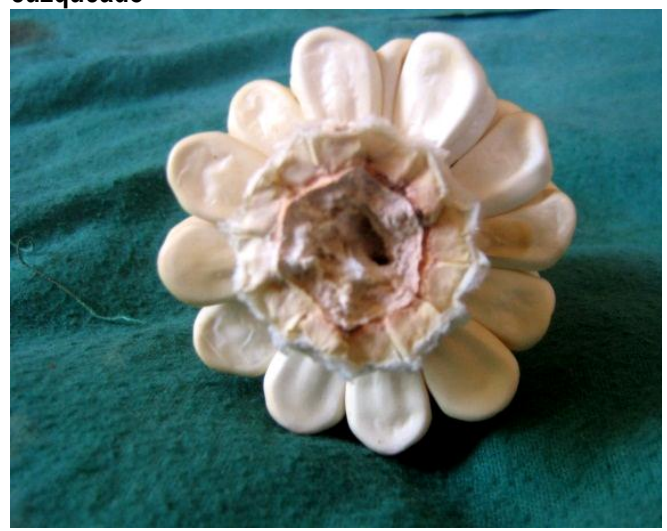

Fotografía 11: Número de hileras DOCE de maíz cuzqueado

El número de granos por hilera es un componente directo del rendimiento y el promedio de la muestra señala uniformidad y calidad de mazorca como se observa en la Fotografía 12.

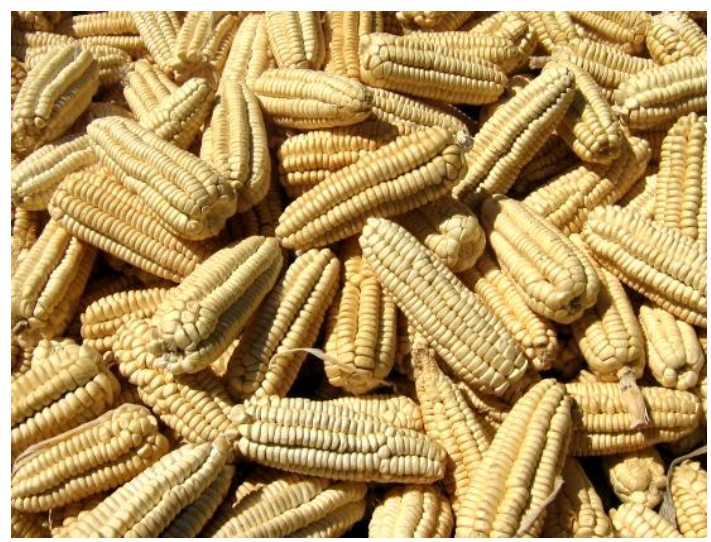

Fotografía 12: Número de granos por hilera de maíz cuzqueado

El Cuadro $\mathbf{N}^{\circ}$ 9, presenta el resumen de las medias y variancias de ocho características evaluadas en la muestra representativa de la población Maíz Cuzqueado. Evidentemente, el genotipo obtenido en términos poblacionales señala la presencia de frecuencias génicas para los loci involucradas en un equilibrio genotípico cercana al ideal de planta. La posibilidad de no alcanzar el techo en el avance genético dependerá de mantener una población numerosa, de la presión e intensidad de selección aplicada, del arte de seleccionar los mejores genotipos y de una adecuada recombinación genética de los componentes directos del rendimiento y calidad del maíz cuzqueado.

La Fotografía 13 nos ilustra el genotipo ideal de planta de la población maíz cuzqueado en choclo y en grano en su doceavo ciclo de selección masal estratificada.

Cuadro $\mathrm{N}^{\circ}$ 9: Medias y variancias de ocho características evaluadas.

\begin{tabular}{lcc}
\hline \multicolumn{1}{c}{ Característica } & Medias & Variancias \\
\hline Días a la floración masculina & 105 & 0.51 \\
Días a la floración femenina & 108 & 0.67 \\
Altura de mazorca & 145.975 & 245.25 \\
Altura de planta & 243.125 & 197.49 \\
Número de hojas & 13.35 & 1.25 \\
Longitud de mazorca & 33.275 & 7.69 \\
Número de hileras por & 9.1 & 2.45 \\
mazorca & 28.625 & 9.62 \\
Número de granos por hilera & 2 \\
\hline
\end{tabular}




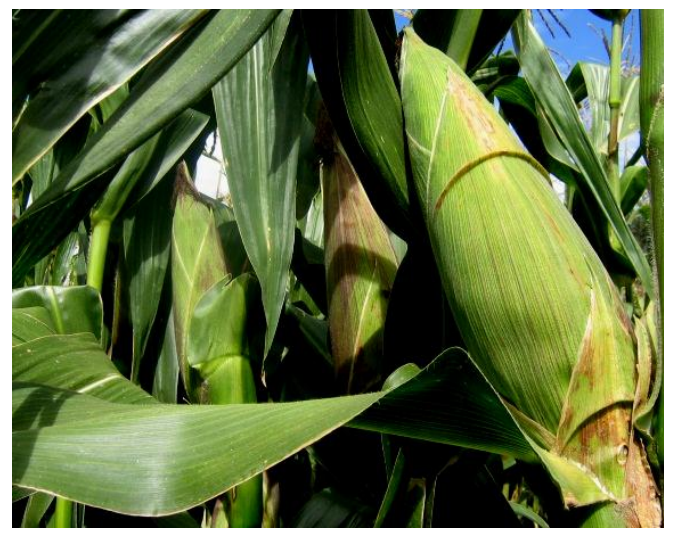

Fotografía 13: Genotipo ideal de maíz cuzqueado

\section{CONCLUSIONES}

- El décimo segundo ciclo de selección masal estratificada del maíz cuzqueado, se ha obtenido una población genéticamente homogénea y heterocigota para los loci que controlan características definidas. Suponiendo que después de cada ciclo de selección existe una disminución de la variancia genética aditiva con la eventualidad de llegar al límite de selección, se aseguró utilizar poblaciones grandes y presiones de selección adecuadas para evitar que los individuos seleccionados no sean una muestra pequeña de aquella generando suficiente variabilidad genética.

- Para días a la floración masculina se observa un promedio de 105 días y 0.51 de variancia, carácter que incide directamente en la precocidad del cultivo y la distancia en días de 3 a la floración femenina aseguran la fertilización de los óvulos de las mazorcas al existir una diferencia adecuada entre la dehiscencia del estambre y la receptividad del gineceo.

- La altura de mazorca de 145.975 centímetros y la variancia de 245.25 evidencia un rango de 0.69 centímetros respecto a la posición de la mazorca en el tallo, ello debido a su ubicación en la sexta, séptima u octava hoja.

- $\quad$ La altura de planta presenta un promedio de 243.125 centímetros y una variancia de 197.49 tomada a los 135 días, la aparente desuniformidad de tamaño de planta es debida a que no todos los genotipos crecen con la misma eficiencia, esta se estandariza al llenado de grano, lo cual quiere decir que al final del ciclo biológico la variancia deberá ser menor.

- El número de hojas con un promedio de 13.25 y una variancia de 1.25 , es el resultado de la adaptación de los individuos a una zona diferente a su origen generando en ella cambios morfológicos propios de la población seleccionada.
- El carácter longitud de mazorca con un promedio de 33.275 centímetros y una variancia de 7.69 señala un ideotipo de producto comercial aceptable para el mercado y sin una amplia variabilidad fenotípica garantiza calidad de producto.

Para el número de hileras por mazorca se obtuvo un promedio de 9.1, esto debido a la presencia de tres tipos de mazorcas: ocho, diez y doce hileras, cuyas frecuencias en la población son determinantes para mantener el equilibrio genotípico.

- En cuanto al número de granos por hilera se obtuvo un promedio de 28.625 granos por hilera en la muestra tomada, de variancia 9.62 siendo un componente importante del rendimiento y calidad de mazorca.

\section{RECOMENDACIONES}

- Respaldar la investigación en el campo del mejoramiento genético de plantas para contar con semillas de calidad.

- Caracterizar morfológicamente caracteres de valor (grano) y genéticamente las familias del compuesto.

- Entregar tecnología de punta a los agricultores para elevar su nivel cultural y social (semilla certificada).

\section{REFERENCIAS BIBLIOGRÁFICAS}

- Borbor, M. 1992. Evaluación de componentes de rendimiento y características morfológicas de compuestos raciales de maíz en la Sierra del Perú. Tesis Mg. Sc. UNA La Molina. Lima, Perú.

- Gamarra, G. 2004. Ganancia Genética por Selección Mazorca Hilera Modificada en tres poblaciones de maíz amiláceo. Tesis Mg. Sc. UNALM. Lima, Perú.

- Chávez, A. J. 1995. Mejoramiento de Plantas II. Métodos específicos para plantas alógamas. Universidad Autónoma Agraria Antonio Narro. Editorial Trillas. México.

- Márquez, F. S. 1991. Genotecnia Vegetal. Métodos, teoría y resultados. AGT. Editorial S-A- Tomo I, II Y III. Progreso 202. Planta Alta C. P. 11800- México.

- Sevilla, R y Holle, E. 2004. Recursos Genéticos Vegetales. Luís León Asociados S.R.L. EDITORES. Lima- Perú.

- Sevilla R. y W. Salhuana, 1970. Comportamiento de semilla de la variedad Blanco Urubamba producida en cuatro ambientes distintos de la Sierra del Perú. Fit. Lat. Vol. 8, No. 1.

- Torregroza C, Manuel. 1985: Principales modificaciones a las técnicas aplicadas en la selección masal en maíz. En: Semillas. Vol. 10, № 4; p. 27-33. 